\title{
Doença autoimune com incidência bucal: nova proposta de tratamento
}

\section{Autoimmune disease with oral incidence: new treatment proposal}

Morgado-Carrasco D, GiavedoniP, Fustà-Novell X, Iranzo P. FR-Rituximab, una revolución en el tratamiento del pénfigo. Actas Dermosifiliogr. 2018;109:177-178.

\author{
Gabriela Lopes dos Santos ${ }^{1}$ \\ ${ }^{1}$ Graduanda de Odontologia - Faculdade de Odontologia \\ de Lins - Universidade Metodista de Piracicaba.
}

Pênfigo é uma doença autoimune que, quando ativa, ocasiona lesões na pele e mucosa bucal dos pacientes, caracterizada também por erosão descamativa. Até 1959 a perspectiva de vida dos pacientes não era favorável, porém a administração de corticosteroides reduziu significativamente as mortes em consequência do pênfigo. Desde então, o uso como protocolo de tratamento com corticoide é padrão. As altas doses do medicamento a longo prazo atingem altas taxas de sucesso, porém, com efeitos adversos consideráveis. A literatura refere-se acerca da possibilidade de medicação imunossupressora, entretanto, sabe-se que as taxas de sucesso são menores quando comparadas com o protocolo padrão.

A utilização de Rituximabe (RTX) é para o tratamento de algumas doenças em que os linfócitos $B$ (células do sistema imunológico) desempenham papel importante. Em decorrência de sua ação, o RTX é utilizado há alguns anos para o tratamento de doenças autoimunes refratárias, como é o caso do pênfigo.

Resultados de publicações recentes mostram estudo randomizado comparando a eficácia da utilização de RTX em associação com prednisona (RTX-LDPRD) com outro grupo tratado, a longo prazo, com altas doses de prednisona, como monoterapia. Essa pesquisa englobou 90 adultos diagnosticados com pênfigo vulgar ou pênfigo foliáceo, não tratados, onde o grupo RTX-LDPRD recebeu $1 \mathrm{~g}$ de RTX nos dias
0 e 14, seguido de $500 \mathrm{mg}$ aos 12 e 18 meses, com 0,5 ou $1 \mathrm{mg} / \mathrm{kg} / \mathrm{dia}$ de prednisona em três meses para doenças moderadas ou seis meses em doenças graves. Por sua vez, o grupo que fazia uso de prednisona como monoterapia recebeu doses de 1 a $1,5 \mathrm{mg} / \mathrm{kg} /$ dia de prednisona no período de 12 a 18 meses. Ambos os grupos foram acompanhados por 36 meses. O estudo mostrou significância estatística aos 24 meses: 89\% (41/46) dos pacientes do grupo (RTXLDPRD) apresentaram remissão completa (CRWT), no período de 277 dias; em contrapartida, o grupo da monoterapia apresentou 34\% (15/44) de melhora em 677 dias. Quando a doença mostrava-se em estágio de remissão, o grupo RTX-LDPRD apresentou ausência dos sinais clínicos por 466 dias, e o grupo controle, 62 dias. Os pacientes apresentaram uma vida plasmática do corticosteroide três vezes maior em relação àqueles que faziam uso de RTX-LDPRD, e também menos efeitos adversos, como os distúrbios endócrinos, musculares e ósseos.

Pacientes tratados com RTX combinados com doses pequenas de corticoides tiveram melhor resposta ao tratamento, resultado mais rápido e com maior tempo de ausência de sinais clínicos, com menos efeitos adversos. O tratamento com os RTX-LDPRD, quando comparado com outros tratamentos, foi $€ 5.500,00$ mais caro, em média de $\mathrm{R} \$ 24,310,00$, entretanto, vale ressaltar que os benefícios citados são 
de grande importância clínica em pacientes que apresentavam recidivas constantes e tratamentos ineficazes.

Qual é a importância desta pesquisa para a Odontologia? Este estudo mostra uma mudança que pode revolucionar o tratamento para esse tipo de doença autoimune, levando a um prognóstico mais favorável nas doenças autoimunes e em diferentes manifestações do pênfigo na cavidade bucal, que apresentava muitas recidivas, resistência a tratamento e manutenção dos achados clínicos. As primeiras manifestações clínicas da doença são suas lesões bucais. ${ }^{1}$ Em muitos casos, essas lesões atingem a gengiva, sob a forma de gengivite descamativa, mas também podem ser vistas sob a forma de lesões bolhosas, que se rompem e deixam dolorosas áreas de erosões em outros locais da cavidade bucal. Alguns profissionais que não apresentam conhecimento acerca das doenças bolhosas e autoimunes tratam o paciente como uma gengivite escamativa padrão, ${ }^{2}$ ou mesmo uma disfunção endócrina, negligenciando um diagnóstico hematológico e realização de biopsia incisional, para diagnóstico correto e encaminhamento a um dermatologista, que acompanhará, com o cirurgião-dentista, o paciente quanto a lesões cutâneas e bucais, respectivamente.

Em se tratando de doença autoimune cutaneomucosa e que promove quadro de exacerbação e remissão com frequência, o tratamento proposto pode não só ajudar no controle das exacerbações, mas também, dirimir os efeitos adversos dos corticosteroides. O resultado da pesquisa demonstra aspecto muito favorável ao uso do RTX-LDPRD, apesar de seu alto custo.

\section{REFERÊNCIAS}

Leite DFC, Macedo M, Simas CMS, Souza LCD, Lopes FF. Pênfigo vulgar na cavidade bucal: relato de caso clínico. RFO UPF. 2015 Dez [citado 2018 Dez 10]; 20(3): 367-371. Disponível em: http://revodonto.bvsalud.org/scielo.php?script=sci_ arttext\&pid=S1413-40122015000300016\&lng=pt.

Zanella RR, Xavier TA, Tebcherani AJ, Aoki V, Sanchez APG. Penfigoide bolhoso no adulto mais jovem: relato de três casos. An. Bras. Dermatol. 2011 Apr [cited 2018 Dec 10]; 86(2): 355-358. Available from: http://www.scielo. br/scielo.php?script=sci_arttext\&pid=S036505962011000200023\&lng=en. http://dx.doi. org/10.1590/S0365-05962011000200023. 